$\mathrm{DE}$

M E D I C I N A

T R O P I C A L

$\mathrm{DE}$

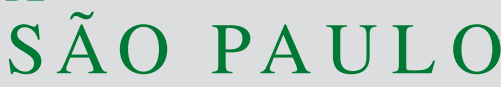

JOURNAL OF THE SÃO PAULO INSTITUTE OF TROPICAL MEDICINE

(1) Universidade Federal do Estado do Rio de Janeiro, Centro de Ciências Biológicas e da Saúde, Hospital Universitário Gaffrée e Guinle, 10aㅡ Enfermaria, Rio de Janeiro, Rio de Janeiro, Brazil

(2) Universidade Federal do Estado do Rio de Janeiro, Centro de Ciências Biológicas e da Saúde, Hospital Universitário Gaffrée e Guinle, Serviço de Anatomia Patológica, Rio de Janeiro, Rio de Janeiro, Brazil.

(3) Fundação Oswaldo Cruz, Instituto Nacional de Infectologia Evandro Chagas, Laboratório de Pesquisa Clínica e Vigilância em Leishmanioses, Rio de Janeiro, Rio de Janeiro, Brazil

Correspondence to: Walter A. Eyer-Silva, Hospital Universitário Gaffrée e Guinle, 10 ${ }^{\text {a }}$ Enfermaria, Rua Mariz e Barros, 775, CEP 20270-004, Rio de Janeiro, RJ, Brazil

E-mail: walter.eyer@ig.com.br

Received: 18 January 2017

Accepted: 20 January 2017

\section{A novel case of human visceral leishmaniasis from the urban area of the city of Rio de Janeiro: autochthonous or imported from Spain ?}

Rio de Janeiro, January 18, 2017

Dear editor

The State of Rio de Janeiro was considered free of human visceral leishmaniasis

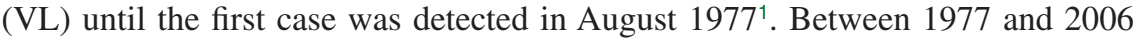
there were a total of 87 confirmed cases, all of which from peri-urban areas close to Pedra Branca and Gericinó Massifs in the West Zone of the city of Rio de Janeiro, Brazil $^{1}$. No new cases occurred in these areas since $2007^{2}$. However, we have recently reported in this journal the case of a 29-year-old woman resident of Cajú neighborhood (central zone) who was diagnosed in January 2013 and whose case was considered by the Municipal Civil Defense and Health Surveillance to be the first instance of autochthonous VL in the urban area of the city of Rio de Janeiro ${ }^{3}$. We now wish to report a novel case of VL we had the opportunity to care for at the same ward of the same university hospital.

A 44-year-old previously healthy male patient was admitted in October 2016 with a one-year history of recurrent fever, anorexia, chronic fatigue, weight loss, increasing abdominal girth, epistaxis, and pedal edema. He sought medical advice on several occasions and at diverse facilities, but his illness remained undiagnosed. Symptomatic drugs were prescribed, as well as iron and cobalamin supplements to treat pancytopenia. His clinical status slowly progressed to a wasting disease.

The patient resided in Brás de Pina (North zone of the city of Rio de Janeiro) since August 2013, when he came back to Brazil after an uninterrupted stay of 23 years in Spain. He was a skilled mason and used to work for a Spanish construction company. In Spain, he lived mainly in the city of Almeria (southeast Mediterranean coast), but frequently traveled and established temporary residence throughout the country, including Madrid, Alicante, Seville and Barcelona. As the patient stated, he went "anywhere they were building something". After returning to Brazil, he established himself in Brás de Pina, where he spent his days in the construction and improvement of his own house. He only left the city for a few days in December 2015 to spend Christmas time in his native town of Belo Horizonte, Minas Gerais State, Brazil.

Clinical examination revealed an undernourished patient, with pallor, tachycardia, tachypnea, hepatomegaly ( $10 \mathrm{~cm}$ from the right costal margin), splenomegaly $(7 \mathrm{~cm}$ below the left costal margin), and ascites (Figure 1). Laboratory evaluations showed a hemoglobin of $8.6 \mathrm{~g} / \mathrm{dL}(13.8-17.2 \mathrm{~g} / \mathrm{dL})$, a total white-cell count of 1,200 per $\mathrm{mm}^{3}$ (4,000-10,000 per $\left.\mathrm{mm}^{3}\right)$, a platelet count of $9.9 \times 10^{4}$ per $\mathrm{mm}^{3}\left(15-45 \times 10^{4}\right.$ per $\left.\mathrm{mm}^{3}\right)$, an albumin of $1.7 \mathrm{~g} / \mathrm{dL}(3.5-5.2 \mathrm{~g} / \mathrm{dL})$, and an activated partial thromboplastin time of $11.7 \mathrm{sec}$. (30-40 sec.). There was no serological evidence of hepatitis B, hepatitis $\mathrm{C}$ or HIV infection and no history of liver disease or alcohol abuse. A diagnosis of VL was made by demonstrating parasites consistent with Leishmania spp. at the amastigote stage of development in the bone marrow aspirate and the biopsy. Culture of a bone marrow aspirate yielded promastigote forms consistent with Leishmania spp. Treatment was initiated in October $13^{\text {th }}, 2016$, with a daily regimen of amphotericin B deoxycholate, starting with escalating doses, until a cumulative dose of $1 \mathrm{~g}$ was reached. He experienced an uneventful recovery, was discharged four weeks later, and is being followed as an outpatient.

We found this case to be noteworthy since it could represent a new case of autochthonous VL in the urban area of the city of Rio de Janeiro. The patient's 


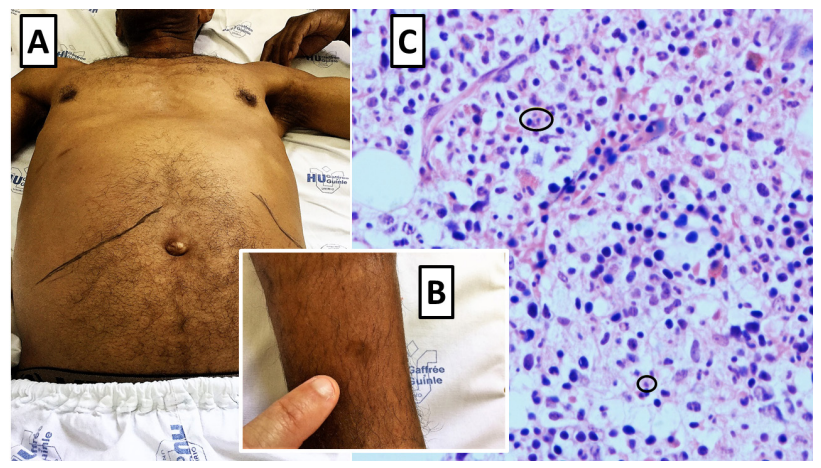

Figure 1 - Clinical images of a 44-year-old male patient diagnosed with VL in the urban area of the city of Rio de Janeiro. Marked hepatosplenomegaly as part of a wasting disease (A). Pitting edema in the anterior aspect of the left shin (B). Bone marrow biopsy stained by hematoxylin and eosin (C) shows a diffuse proliferation of histiocytes and intracellular forms (black circles) of Leishmania spp. amastigotes (original magnification $400 \mathrm{x}$ ).

house is located less than $10 \mathrm{~km}$ far from the neighborhood of Cajú, where our previous patient resided. We consider highly unlikely that he could have acquired this protozoal infection during the brief escape to celebrate Christmas in Belo Horizonte, since he was already symptomatic. Alternatively, we found it inevitable to raise the possibility of his infection having been acquired in Spain. In fact, Spain is experiencing an unprecedented outbreak of canine and human cutaneous and VL since $2009^{5}$. The disease is recorded nearly everywhere in the Peninsula and Balearic Islands, but seems to have hit more severely the outskirts of Madrid ${ }^{6,7}$. A time span of 26 months separates his arrival in Rio de Janeiro and the start of his symptomatic disease. The incubation period of VL is in general, considered to be between two to eight months, and such a long interval may be unusual, but is not unknown. Descriptions of $24^{8}, 34^{9}$, and at least 48 months $^{10}$ between the exposure and the onset of disease have been reported. Moreover, an insidious onset of disease could have passed unnoticed.

We should constantly monitor and be prepared for changes in the epidemiology of the leishmaniases. In Spain, both cutaneous and VL are caused by species Leishmania (Leishmania) infantum ${ }^{11}$. Likewise, this species, also known as Leishmania (Leishmania) chagasi, is the etiological agent of VL in Brazil and in the Americas. In contrast, in the State of Rio de Janeiro, almost all cases of American tegumentary leishmaniasis (ATL) are caused by Leishmania (Viannia) braziliensis $^{12}$. It is remarkable that soon after our first report of autochthonous VL from an urban area of the city of Rio de Janeiro ${ }^{3}$, two cases of ATL were diagnosed from the same Cajú neighborhood ${ }^{13}$, but the species could not be identified. Interestingly, this was followed by the first report of ATL caused by Leishmania (Leishmania) infantum in an urban area of Rio de Janeiro ${ }^{14}$. The patient, an 81-year-old woman, was also resident of Cajú neighborhood. All these observations followed the diagnosis of 25 cases of canine VL in Cajú neighborhood in $2011^{15}$.

At present, it remains unclear whether the patient reported herein represents a novel urban autochthonous case or if the disease was imported from Spain. Maybe future studies will help us clarify this issue. The former hypothesis should ring further alarm bells in surveillance and control programs. The latter reminds us that imported leishmaniasis should be regarded as a major travel medicine concern ${ }^{16}$ when travelling to endemic countries, and even to non-endemic ones if confirmed cases have already been reported. What is undisputable is that if not suspected and left untreated, VL has devastating consequences. The fact that our patient's illness remained undiagnosed for one year suggests that the awareness of the clinical spectrum of VL has waned. It is of great clinical and epidemiological importance that physicians be familiar with the presentation patterns of leishmaniases, so that these diagnoses will not be missed or delayed.

Taken together, these cases of ATL and VL highlight the urgent need of surveillance and control programs in the city of Rio de Janeiro, including the active search of human and canine cases. The recent explosive Spanish outbreak should be taken as an alert to other areas where favorable eco-epidemiological conditions may exist.

\section{CONFLICT OF INTEREST}

The authors declare there is no conflict of interest.

\section{INFORMED CONSENT}

The informed consent of the patient was obtained for publication of the case.

Guilherme Almeida Rosa da Silva ${ }^{1}$ Walter de Araujo Eyer-Silva ${ }^{1}$ Marilza Campos de Magalhães ${ }^{1}$ Fernando Raphael de Almeida Ferry ${ }^{1}$ Jorge Francisco da Cunha Pinto ${ }^{1}$ Marcelo Costa Velho Mendes de Azevedo ${ }^{1}$ Rogério Neves-Motta ${ }^{1}$ Carolina Cunto de Athayde ${ }^{1}$ Pablo Jordão ${ }^{1}$

Rodrigo Panno Basílio-de-Oliveira ${ }^{2}$ Marcelo Rosandiski Lyra ${ }^{3}$ Aline Fagundes ${ }^{3}$ Maria Inês Pimentel ${ }^{3}$ Raquel da Silva Pacheco ${ }^{3}$ Maria de Fátima Madeira ${ }^{3}$ Mauro Celio de Almeida Marzochi ${ }^{3}$ 


\section{REFERENCES}

1. Marzochi MC, Fagundes A, Andrade MV, Souza MB, Madeira MF, Mouta-Confort E, et al. Visceral leishmaniasis in Rio de Janeiro, Brazil: eco-epidemiological aspects and control. Rev Soc Bras Med Trop. 2009;42:570-80.

2. Marzochi MC. Visceral leishmaniasis in Southern Rio de Janeiro State and the risk of propagation to São Paulo State, Brazil. Rev Soc Bras Med Trop. 2016;49:147-9.

3. Silva GA, Boechat TO, Ferry FR, Pinto JF, Azevedo MC, Carvalho RS, Motta RN, Veras MF. First case of autochthonous human visceral leishmaniasis in the urban center of Rio de Janeiro: case report. Rev Inst Med Trop Sao Paulo. 2014;56:81-4.

4. Miró G, Checa R, Montoya A, Hernández L, Dado D, Gálvez R. Current situation of Leishmania infantum infection in shelter dogs in northern Spain. Parasit Vectors. 2012;5:60.

5. Herrador Z, Gherasim A, Jimenez BC, Granados M, San Martín $\mathrm{JV}$, Aparicio P. Epidemiological changes in leishmaniasis in Spain according to hospitalization-based records, 1997-2011: raising awareness towards leishmaniasis in non-HIV patients. PLoS Negl Trop Dis. 2015;9:e0003594.

6. Arce A, Estirado A, Ordobas M, Sevilla S, García N, Moratilla $\mathrm{L}$, et al. Re-emergence of leishmaniasis in Spain: community outbreak in Madrid, Spain, 2009 to 2012. Euro Surveill. 2013;18:20546.

7. Carrillo E, Moreno J, Cruz I. What is responsible for a large and unusual outbreak of leishmaniasis in Madrid? Trends Parasitol. 2013;29:579-80.

8. Matzdorff AC, Matthes K, Kemkes-Matthes B, Pralle H. [Visceral leishmaniasis with an unusually long incubation time]. Dtsch Med Wochenschr. 1997;122:890-4.

9. Stone HH, Tool CD, Pugsley WS. Kala-azar (visceral leishmaniasis): report of a case with 34 month incubation period and positive Doan-Wright test. Ann Intern Med 1952;36:686-93
10. Neto VA. [Visceral leishmaniasis with an incubation period of at least 4 years]. Rev Inst Med Trop Sao Paulo. 1978;20:312-4.

11. Chicharro C, Llanes-Acevedo IP, García E, Nieto J, Moreno J, Cruz I. Molecular typing of Leishmania infantum isolates from a leishmaniasis outbreak in Madrid, Spain, 2009 to 2012. Euro Surveill. 2013;18:20545.

12. Oliveira-Neto MP, Mattos MS, Perez MA, Da-Cruz AM, Fernandes O, Moreira J, et al. American tegumentary leishmaniasis (ATL) in Rio de Janeiro State, Brazil: main clinical and epidemiologic characteristics. Int J Dermatol. 2000;39:506-14.

13. Bernardes Filho F, Bonatto DC, Martins G, Maier LM, Nery JA, Azulay-Abulafia L. Occurrence of two autochthonous cases of American cutaneous leishmaniasis in the neighborhood of Caju, city of Rio de Janeiro, Brazil. An Bras Dermatol. 2014;89:848-50.

14. Lyra MR, Pimentel MI, Madeira MF, Antonio LF, Lyra JP, Fagundes A, et al. First report of cutaneous leishmaniasis caused by Leishmania (Leishmania) infantum chagasi in an urban area of Rio de Janeiro, Brazil. Rev Inst Med Trop Sao Paulo. 2015;57:451-4.

15. Rio de Janeiro, Município do. Secretaria Municipal de Saúde e Defesa Civil. Nota Técnica 1/2011/S/SUBVISA/SVFSZ. Orientações sobre vigilância, prevenção e controle da Leishmaniose Visceral (LV) em caninos, no município do Rio de Janeiro (MRJ), em virtude da confirmação de transmissão canina da doença, no bairro do Caju - Área Programática 1.0. [cited 2017 Jan 12]. Available from: http://www.crmvrj.org. br/nota\%20tecnica\%20Leishmaniose_SUBVISA.pdf .

16. Neghina R, Neghina AM. Leishmaniasis, a global concern for travel medicine. Scand J Infect Dis. 2010;42:563-70. 